Xinxin $\mathrm{Ai}$ and Yumei Yue*

\title{
Microstructure and Mechanical Properties of Friction Stir Processed A356 Cast Al under Air Cooling and Water Cooling
}

https://doi.org/10.1515/htmp-2017-0036

Received March 14, 2017; accepted July 25, 2017

\begin{abstract}
In this work, friction stir processing (FSP) was used to modify the microstructure of A356 cast aluminum alloy under air cooling and water cooling conditions. The microstructure and mechanical properties of air cooling and water cooling FSP specimens and their differences were mainly discussed. Results show that the grains can be significantly refined after FSP under both air cooling and water cooling conditions. The water cooling FSP specimen shows much smaller grains than the air cooling FSP specimen due to lower temperature. Similarly, the Si particles of water cooling FSP specimen show much smaller sizes and better distribution. Both the air cooling FSP specimen and water cooling FSP specimen own much higher tensile strength and elongation than A356 base material (BM). In particular, the tensile strength and elongation of water cooling specimen are respectively 231 Mpa and $14.15 \%$, which are equal to $186.3 \%$ and $1088.5 \%$ of the BM. Furthermore, the microhardness of water cooling FSP specimen is lower than that of the air cooling FSP specimen.
\end{abstract}

Keywords: friction stir processing, water cooling, microstructure, Si particles, tensile strength

\section{Introduction}

Friction stir processing (FSP) is a novel solid-state microstructure moderation technology, which was invented by Mishra et al. [1]. The FSP process is achieved by inserting a rotating tool into a single sheet and moves it along a predetermined line and distance. During FSP, a portion of plastic material flows from the advancing side (AS) to the

*Corresponding author: Yumei Yue, Faculty of Aerospace Engineering, Shenyang Aerospace University, No. 37 Daoyi South Avenue, Daoyi Development District, Shenyang 110136, China, E-mail: superjsd@163.com

Xinxin Ai, Faculty of Aerospace Engineering, Shenyang Aerospace University, No. 37 Daoyi South Avenue, Daoyi Development District, Shenyang 110136, China, E-mail: sau_yueyumei@163.com retreating side (RS) of the rotating tool. Undergone intense plastic deforming and heat input, the microstructure of base material (BM) changes its original features and is always characterized by finer morphologies [2-4]. In recent years, FSP process has attracted more and more attention and has been used to modify microstructure feature [5], achieving super-plastic of some certain materials [6] and preparing nano-composites [7].

Since the invention of FSP, a plenty of investigations have been done by the researchers to investigate the microstructure and mechanical properties of FSP specimens. Mishra et al. [1] FSPed 7075 aluminum alloy and obtained grains size about $3.3 \mu \mathrm{m}$. Kwon et al. [8] studied 1050 aluminum alloy FSP specimen and found that when using the rotating speed of $560 \mathrm{rpm}$, the hardness and tensile strength of the processed zone increased by $37 \%$ and $46 \%$ compared with those of the BM. Cui et al. [9] obtained grains with average sizes from $2.7 \mu \mathrm{m}$ to $13.4 \mu \mathrm{m}$ on 5083-H112 FSP specimen. Ma et al. [10] FSPed commercial $7075 \mathrm{Al}$ rolled plates and reported that the average size of grains was $7.5 \mu \mathrm{m}$ and $3.8 \mu \mathrm{m}$ when using 4 $\mathrm{ipm} / \mathrm{rpm}$ and $6 \mathrm{ipm} / \mathrm{rpm}$.

Although being a solid-state technology, too much heat input during FSP can still result into the coarseness of microstructure and the decrease of the mechanical properties of the processed zone. Therefore, some researchers tried cooling methods to reduce the heat input during FSP. Feng et al. [11] performed underwater FSP on 2219-T6 Al alloy and obtained grain size smaller than $1 \mu \mathrm{m}$. Su etal. [12] used the mixture of water, methanol and dry ice as the cooling method during FSP of $7075 \mathrm{Al}$ alloy and obtained average size about 100-400 $\mathrm{nm}$. Liu et al. [13] found that during the FSP process of Al$\mathrm{Zn}-\mathrm{Mg}-\mathrm{Cu}$ alloy, the average grain size of processed zone undergone water cooling was about $0.8 \mu \mathrm{m}$, which was much smaller than the conventional air cooling condition.

Based on the references [11-13], it can be seen that the water cooling method is an effective method to decrease the heat input and grain sizes during FSP. However, studies about the effect of water cooling method on FSP of Al-Si-Mg Al alloy are few. Therefore, 
in this work, an Al-Si-Mg alloy (A356) was chosen as the BM. The effect of water cooling method on the microstructure and mechanical properties of FSP specimens were mainly discussed.

\section{Experiment}

The BM used in this work is $5 \mathrm{~mm}$-thick A356 alloy. Figure 1 shows the BM microstructure of the A356 cast aluminum alloy. A356 is an Al-Si-Mg alloy. The BM consists of big $\alpha-\mathrm{Al}$ matrix and eutectic $\mathrm{Si}$ particles. The dimensions of the workpiece are $200 \mathrm{~mm} \times 200 \mathrm{~mm}$. The main components of the $\mathrm{BM}$ are $7 \% \mathrm{Si}, 0.3 \% \mathrm{Mg}$ and bal $\mathrm{Al}$. The FSP experiment was performed on a FSW-3LM-4012 machine. The tool used during the experiment is made of $\mathrm{H} 13$ steel. The shoulder diameter of the rotating tool is $18 \mathrm{~mm}$. Diameters of the pin tip and bottom are $4 \mathrm{~mm}$ and $6 \mathrm{~mm}$, respectively. The length of pin is $4 \mathrm{~mm}$. The title angle of tool axis was kept at $2.5^{\circ}$ during the whole FSP process. The tool rotating speed and welding speed during welding were $1000 \mathrm{rpm}$ and $50 \mathrm{~mm} /$ min, respectively. Shoulder plunge depth was $0.1 \mathrm{~mm}$. During the water cooling FSP process, water was directly sprayed toward the processed zone after the tool movement, as shown in Figure 2. The water cooling process lasted another $20 \mathrm{~s}$ after the FSP process.

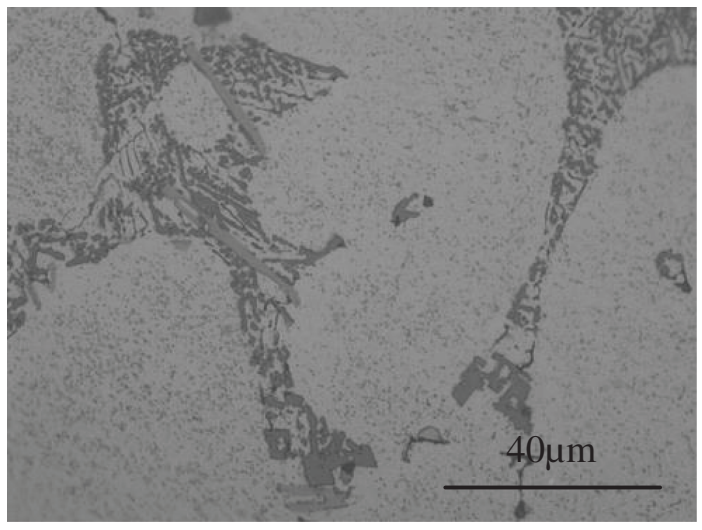

Figure 1: The microstructure of A356 BM.

After the FSP process, metallographic samples and tensile specimens were cut using an electrical discharge cutting machine. Dimensions of the tensile specimen and its intercepted region are shown in Figure 3. After burnished, polished and etched with $12 \mathrm{ml} \mathrm{HCL}+6 \mathrm{ml}$ $\mathrm{HNO}_{3}+1 \mathrm{ml} \mathrm{HF}+1 \mathrm{ml} \mathrm{H}_{2} \mathrm{O}$, metallographic analysis was carried out on an optical microscopy (OM, Olympus-

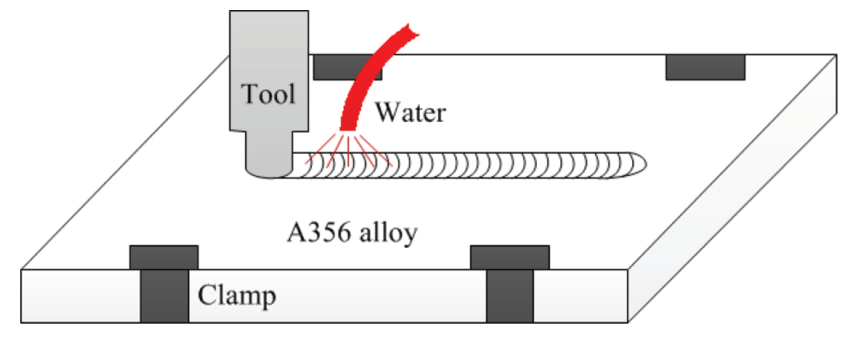

Figure 2: Schematic of the water cooling FSP process.

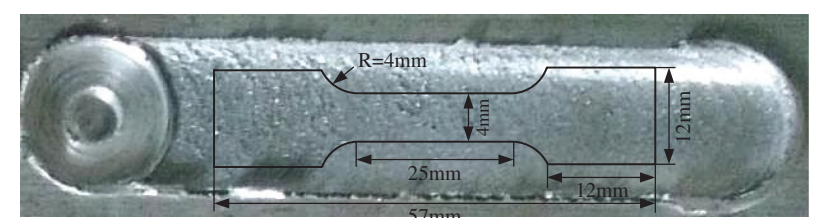

Figure 3: Dimensions of the FSP specimen.

GX71). Tensile tests were performed on a computer-controlled universal tensile testing machine. A constant speed of $5 \mathrm{~mm} / \mathrm{min}$ was used during the testing process. After that, the fracture surfaces were analyzed using a scanning electron microscope (SEM).

\section{Results and discussion}

\section{Grain sizes}

Figure 4 shows the grains at the different regions of these two FSP specimens. The regions are taken from the upper, middle and lower regions of processed zone. During the FSP process, complete dynamic recrystallization happens in the processed zone and fine grains can be obtained at all the regions. For the air cooling FSP specimen, it is seen in Figure 4(b) that the middle region of the processed zone owns the biggest grain sizes. The upper and lower regions of the processed zone own much smaller grains than the middle region, as shown in Figure $4(\mathrm{a}-\mathrm{c})$. Possible region for this can be attributed to relative longer high-temperature duration time at the middle region. Figure $4(\mathrm{~d}-\mathrm{f})$ shows the grains of the water cooling FSP specimen. It can be seen that the grains at all these three regions own much smaller sizes compared to the air cooling FSP specimen. This is because the coarseness of microstructure is significantly restrained under the water cooling condition. As is wellknown, too much heat input during FSP or FSW process can result into serious grain coarseness, which not only 

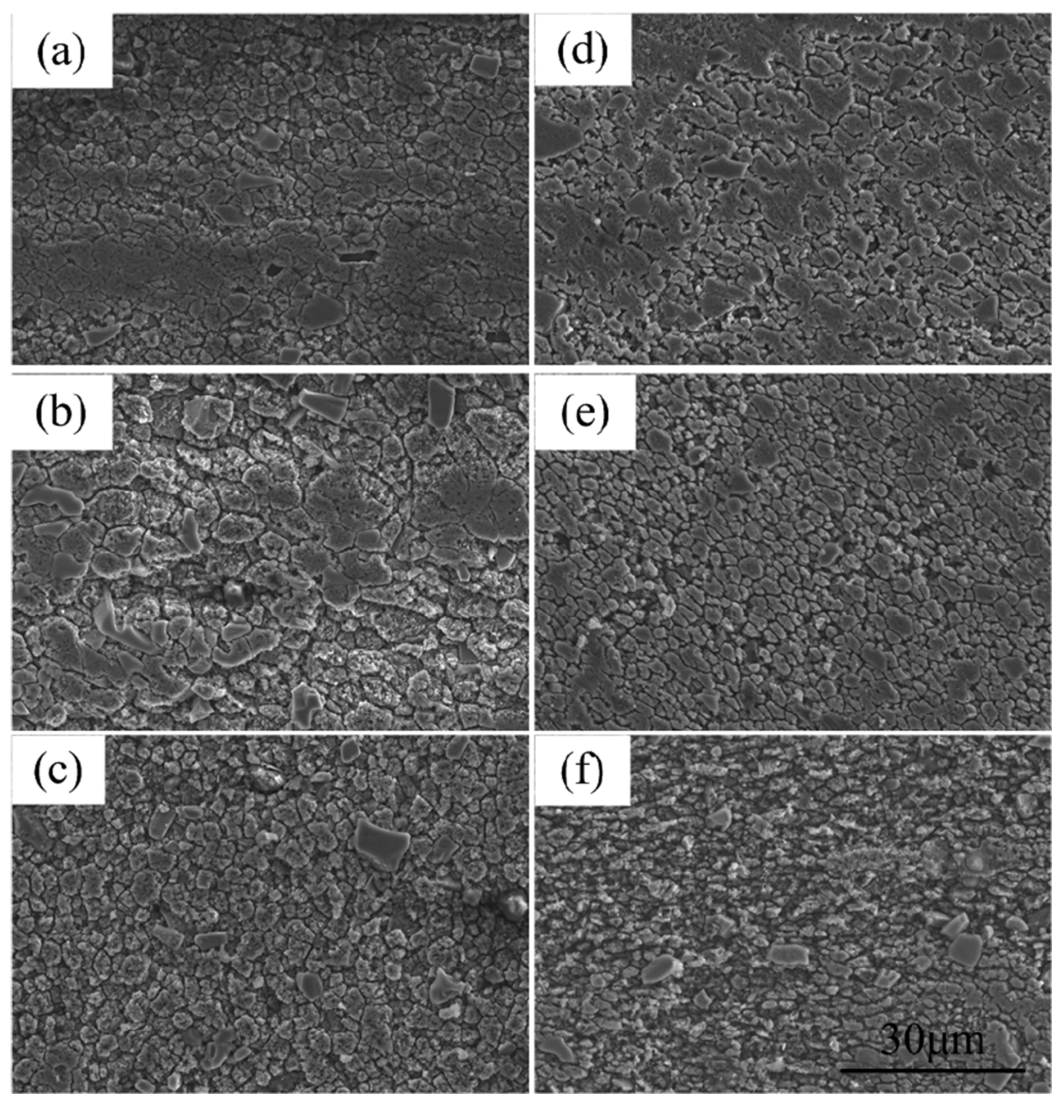

\section{(f)}

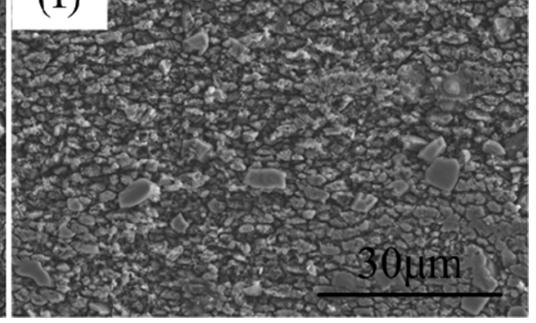

Figure 4: Grains at different regions: (a) upper, (b) middle and (c) lower region of air cooling FSP specimen, (d) upper, (e) middle and ( $f$ ) lower region of water cooling FSP specimen. decreases the hardness but also reduces the elongation $[15,16]$. During the water cooling process, the temperature of the processed zone can be largely decreased because the water takes away a plenty of the heat. Lower heat input can significantly reduce the grain coarseness. Due to the high thermal conductivity of the A356 $\mathrm{Al}$, all the temperatures of different region in the processed zone are reduced. Therefore, much smaller grains can be obtained in Figures 3(d-3f). Figure 5 shows the average grain size at different regions of these two specimens. For the air cooling FSP specimen, the average grain size of middle region is $6 \mu \mathrm{m}$, which is much bigger than that of the water cooling FSP specimen $(3 \mu \mathrm{m})$. Similarly, the grains at the upper and lower regions of water cooling FSP specimen are both smaller than those of the air cooling FSP specimen. The grain sizes in Figures 4 and 5 illustrate the water cooling process can effectively restrain the growing of the grains. In the work of Ma et al [5], they used different tools during FSP of A356 Al and obtained uniform fine-grained structure of 5-8 $\mu \mathrm{m}$ with uniformly distributed Si particles. In their another work [14], they used rotating speeds lower than 1000 rpm using FSP of A356 and obtained a microstructure with fine grain sizes from (3 to $4 \mu \mathrm{m}$ ).

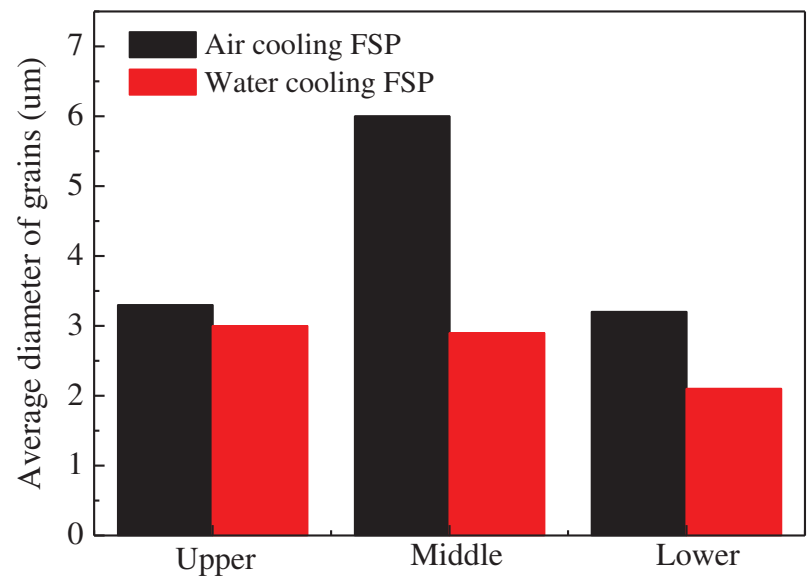

Figure 5: Average sizes of the SZ grains.

\section{Si particles}

Figure 6 shows the Si particles distribution at the upper, middle and lower regions of the air cooling and water cooling FSP specimens. On the air cooling FSP joint, the lower region of the processed zone owns the maximum Si sizes, as shown in Figure 6(c). The upper and middle regions of the specimen own the 

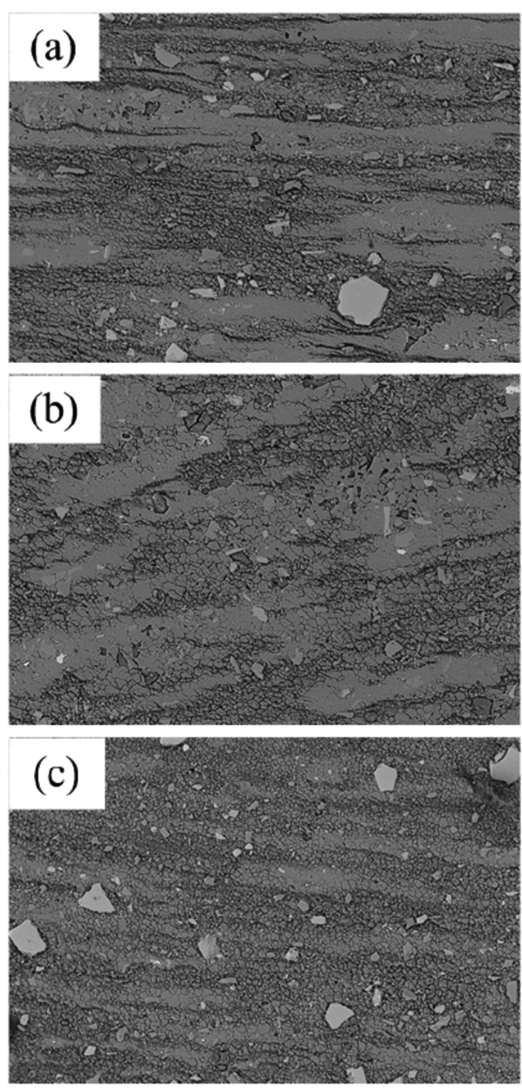

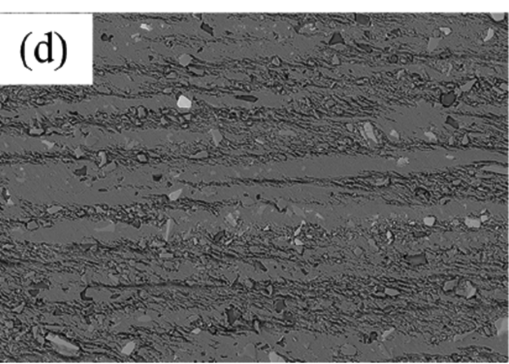

\section{(e)}

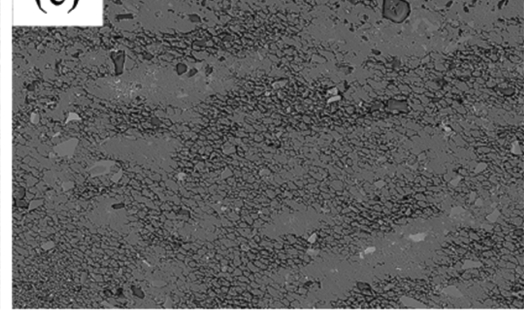

(f)

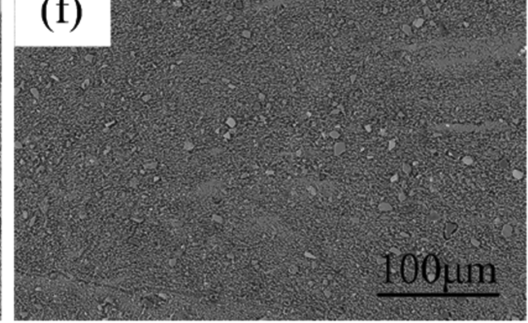

Figure 6: Si particles distribution: (a) upper, (b) middle and (c) lower regions of air cooling FSP specimen, (d) upper, (e) middle and (f) lower regions of water cooling FSP specimen. minimum Si sizes, as shown in Figures 6(a-b). The Si particles show the most excellent distribution at the middle region (Figure 6b). Some Si particles with irregular boundaries can be observed at the lower region of the processed zone (Figure 6c). Possible reason for this may be the insufficient mechanical stirring action of the tool at the lower processed zone region. Compared with the air cooling FSP specimen, the Si particles are much well distributed on the water cooling FSP specimen, as shown in Figures 6(d-f). Under the water cooling condition, the Si particles with much smaller sizes are obtained at all regions of the processed zone. The sizes of Si particles are similar and only the ones at the upper processed zone show a little increase. Besides, it can be seen in Figures 6(d-f) that the Si particles are much well distributed at all the three regions of the water cooling FSP specimen. According to Ma et al. [14], the high density of fine Si particles exerted a significant effect on the recrystallization process and subsequent grain growth during FSP, affecting the eventual fine-grained structure. Compared with the air cooling FSP specimen, the high density of Si particles on the water cooling FSP specimen obviously restricts the grain growth after processing. Therefore, the grains with smaller sizes can be observed in Figures 6(d-f). In fact, the effect of the Si particles only plays a subordinate effect on the grain sizes. The main reason is the lower temperature under the water cooling FSP process [17-19]. However, size of the Si particles obtained in this work is a little bigger than the works of Ma et al. [5, 14]. Possible reason for this may be the BM differences of the BM.

\section{Mechanical properties}

\section{Tensile properties of the specimens}

Figure 7 shows the tensile properties and the elongations of the air cooling FSP and water cooling FSP specimens. To compare with those of the BM, tensile specimens with the same size in Figure 2 were cut and their tensile strengths were also tested. It can be seen that both the tensile strength and elongation of the FSP specimens are much higher than those of the BM. The tensile strength and the elongation are much higher for the water cooling FSP specimen. The BM specimen of cast $\mathrm{A} 356 \mathrm{Al}$ owns a tensile strength of $124 \mathrm{Mpa}$ and an elongation of $1.30 \%$. 


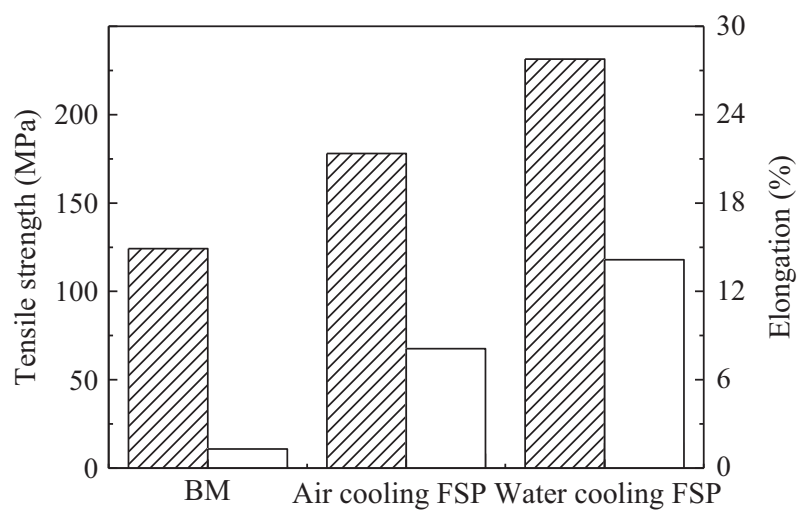

Figure 7: Tensile properties of these specimens.

The tensile strength of air cooling FSP specimen shows a $43.5 \%$ increase in the tensile strength and a $523.8 \%$ increase in elongation, which are $178 \mathrm{Mpa}$ and $8.11 \%$, respectively. For the water cooling specimen, the tensile strength and elongation are respectively $231 \mathrm{Mpa}$ and $14.15 \%$, which are equal to $186.3 \%$ and $1088.5 \%$ of those of BM. Figure 8 shows the load displacement curves of the air cooling FSP specimen and water cooling FSP specimen. The BM specimen fractures immediately after reaching the highest load point. The two curves of FSP specimens show similar morphologies. Before reaching the maximum load, the curves show rather slow ascending morphologies. The water cooling FSP specimen shows obvious higher failure load and displacement before failure. This can be attributed finer grains of the processed zone, as shown in Figures 3 and 4. Besides, the well-distributed $\mathrm{Si}$ particles of the water cooling specimen also play an important role in tensile strength and elongation of the testing specimen.

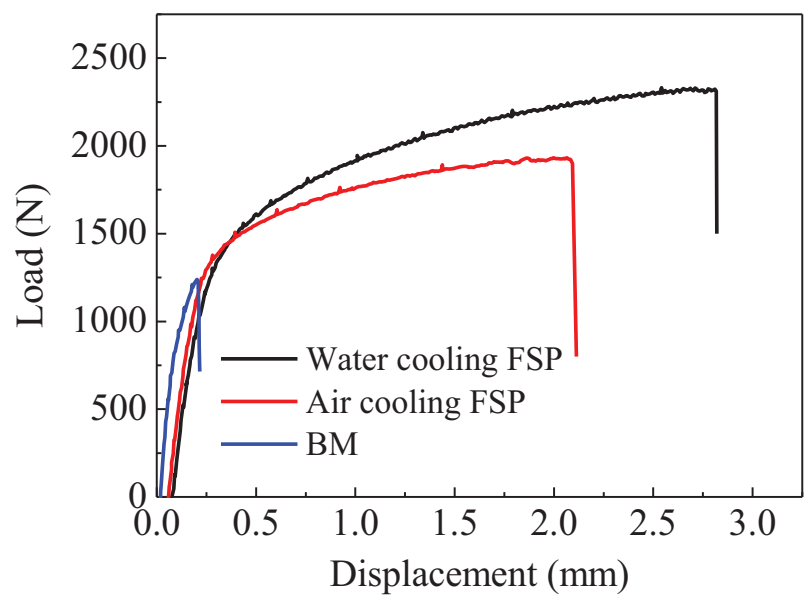

Figure 8: Load-displacement curves of these specimens.

\section{Fracture morphologies}

Figure 9 shows the fracture morphologies of the air cooling and water cooling FSP specimens. As shown in Figure 9(a), a plenty of dimples can be seen. The dimples show different sizes and depth, indicating the ductile fracture mode. Figure 9(b) shows the fracture morphology of water cooling specimen. It can be seen that the sizes of the dimples are much smaller than that of the air cooling specimen. Different fracture morphologies can be attributed the sizes of the grains and Si particles. The fracture morphology of the water cooling specimen also indicates ductile fracture mode.
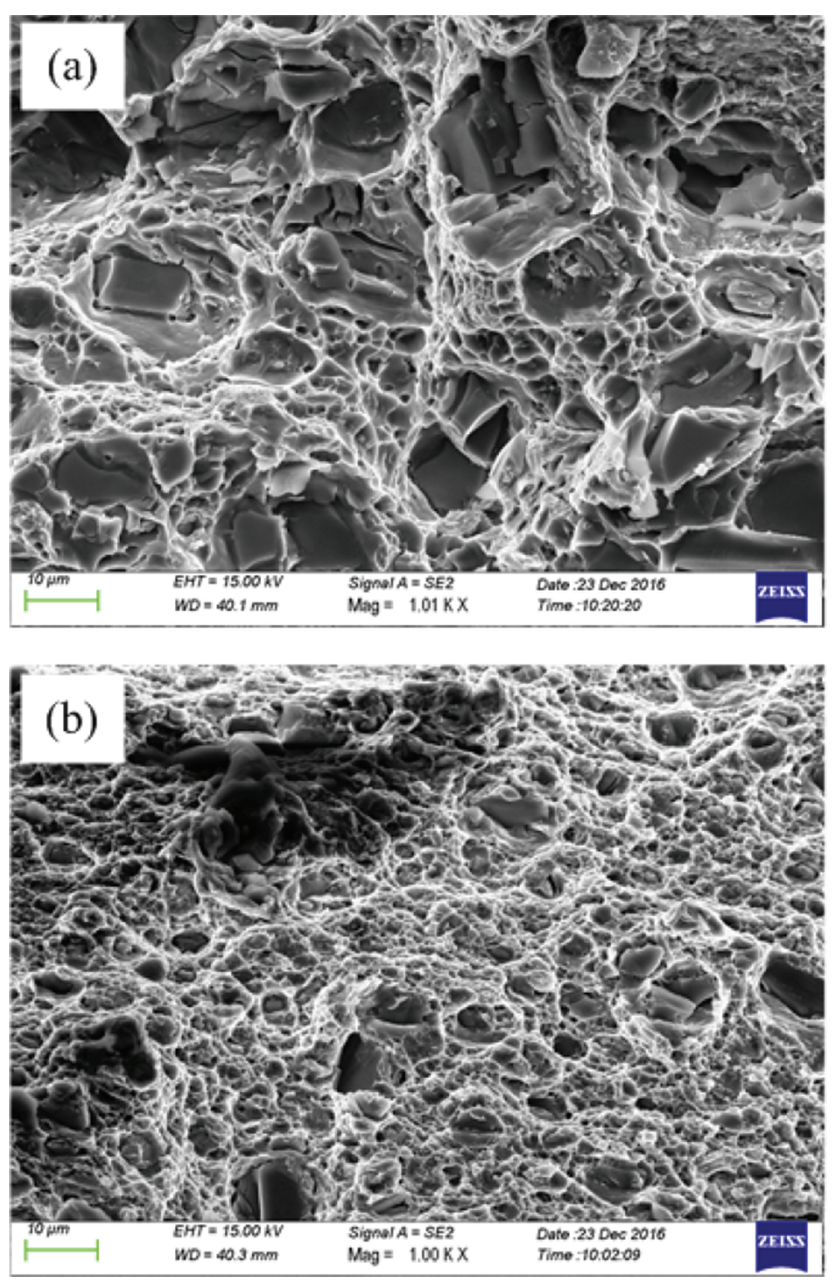

Figure 9: Fracture morphologies of (a) air cooling specimen and (b) water cooling specimen.

\section{Microhardness of the FSP specimens}

To further compare the mechanical properties of these different specimens, the hardness of processed zone was 
tested. Figure 10 shows the hardness testing line of the specimens. The testing machine was HVS-1000 Vickers hardness tester. The testing step was $0.5 \mathrm{~mm}$. The testing force of $200 \mathrm{~g}$ was applied and the dwell time was $10 \mathrm{~s}$. Figure 11 shows the hardness curves along the three testing lines. It can be seen that the hardness curves of different specimens and along the three different testing lines show rather similar morphologies. The hardness values of the processed zone are higher than that of the BM. Adjacent to the processed zone, the thermalmechanically affected zone (TMAZ) and the heat affected one (HAZ) own lower hardness values. Along all the three testing lines, the hardness of the water cooling specimen is lower than that of the air cooling FSP specimen, as shown in Figure 11. As shown in

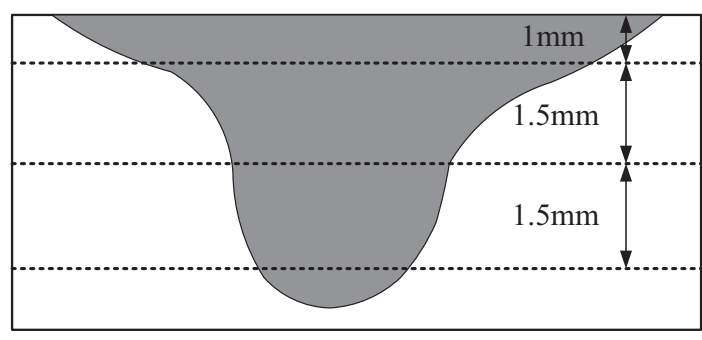

Figure 10: Schematic of the hardness testing lines.
Figures 3 and 5, the grains and Si particles own not only smaller sizes but also better distribution on the water cooling FSP specimen, which is beneficial to hardness increase. The hardness difference in Figure 11 can be attributed to the Si particles, which have higher hardness. According to the work of Ma et al. [5], when using $900 \mathrm{rpm}$ and $203 \mathrm{~mm} / \mathrm{min}$, the temperature which is $5 \mathrm{~mm}$ to the joint center reaches $478^{\circ} \mathrm{C}$. This high temperature resulted into the growth of secondary phase particles, leading to high hardness. It is no doubt that the temperature of during the water cooling FSP process is lower than that of the air cooling FSP process. This restricts the growth of secondary phase particles and causes it to dissolve into the $\mathrm{Al}$ matrix. Hence lower hardness values of the water cooling FSP specimen were attained.

To conclude, the FSP process can be used to improve the mechanical properties of A356 cast aluminum alloy. Firstly, big Si particles can be broken and then dissolve into the BM, which is beneficial to increase the tensile strength and elongation. Secondly, big grains can be refined after the FSP process. Smaller grains are also beneficial to mechanical properties according to HallPetch equation. After the water cooling process, both the grain and the Si particles show smaller sizes and better distributions.
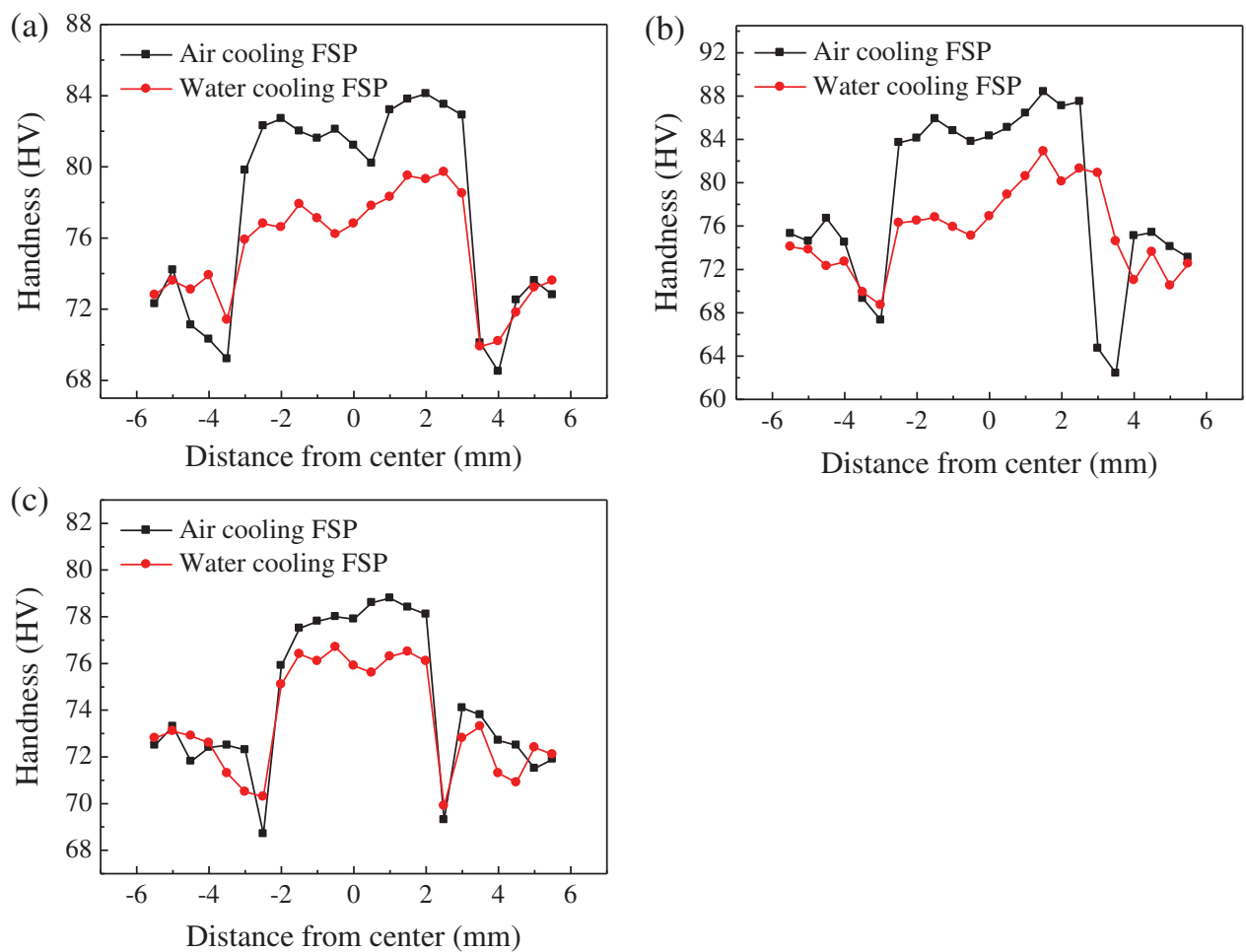

Figure 11: The hardness of processed zone: (a) upper line, (b) middle line and (c) lower line. 


\section{Conclusions}

In this work, an Al-Si-Mg alloy (A356) cast aluminum alloy was FSPed under air cooling and water cooling conditions. The microstructure and mechanical properties of these two specimens were mainly investigated and compared. The following conclusions can be drawn:

(1) The grains of the processed zone can be refined after FSP. The water cooling FSP method owned a better grains refinement effect. The grain size of the water cooling FSP specimen is much smaller than that of the air cooling FSP specimen.

(2) The Si particles inside the processed zone show smaller sizes and better distribution on the water cooling FSP specimen.

(3) Both the air cooling FSP specimen and water cooling FSP specimen own much higher tensile strength and elongation than the BM. In particular, the ensile strength and elongation of the water cooling specimen are respectively $231 \mathrm{Mpa}$ and $14.15 \%$, which are equal to $186.3 \%$ and $1088.5 \%$ of those of the BM.

Funding: This work is supported by the National Natural Science Foundation of China (No. 51204111).

\section{References}

[1] R.S. Mishra and M.W. Mahoney, Materials. Science. Forum., 357-359, 3 (2001) 507-514.
[2] N. Saito, I. Shigematsu, T. Komaya, T. Tamaki and G. Yamauchi, J. Mater. Sci. Lett., 20(20) (2001) 1913-1915.

[3] Y.J. Kwon, N. Saito and I. Shigematsu, J. Mater. Sci. Lett., 21(19) (2002) 1473-1476.

[4] R.S. Mishra, M.W. Mahoney, S.X. Mcfadden, N.A. Mara and A.K. Mukherjee, Scripta. Mater., 42(2) (1999) 163-168.

[5] Z.Y. Ma, S.R. Sharma and R.S. Mishra, Metall. Mater. Trans. A., 37A (2006) 3323-3336.

[6] F.C. Liu and Z.Y. Ma, Scripta. Mater., 59 (2008) 882-885.

[7] C.J. Lee, J.C. Huang and P.J. Hsieh, Scripta. Mater, 54 (2006) 1415-1420.

[8] Y.J. Kwon, I. Shigematsu and N. Saito, Scripta. Mater., 49(8) (2003) 785-789.

[9] G.R. Cui, Z.Y. Ma and S.X. Li, Acta. Mater, 57 (2009) $5718-5729$.

[10] Z.Y. Ma, R.S. Mishra and M.W. Mahoney, Acta. Mater, 50 (2002) 4419-4430.

[11] X. Feng, H. Liu and S.S. Babu, Scripta. Mater, 65 (2011) 1057-1060.

[12] J. Su, T.W. Nelson and C.J. Sterling, Scripta. Mater, 52 (2005) 135-140.

[13] F.C. Liu and Z.Y. Ma, Scripta. Mater, 58 (2008) 667-670.

[14] Z.Y. Ma, S.R. Sharma and R.S. Mishra, Mater. Sci. Eng. A., 433 (2006) 269-278.

[15] Z. Li, Y. Yue, S. Ji, P. Chai and Z. Zhou, Mater. Des., 90(15) (2016) 238-247.

[16] H.J. Liu, J.Q. Li and W.J. Duan, Int. J. Adv. Manuf. Technol., 64 (1685-1694) 2013.

[17] R. Yang, Z. Zhang, Y. Zhao, G. Chen, Y. Guo, M. Liu and J. Zhang, Mater. Charact., 106 (2015) 62-69.

[18] K. Dehghani and A. Chabok, Mater. Sci. Eng. A, 528 (2011) 4325-4330.

[19] L. Fratini, G. Buffa and R. Shivpuri, Acta Mater., 58(6) (2010) 2056-2067. 